\title{
Effectiveness of Play Therapy during Hospitalization in reducing Anxiety among 6- 12 Years Children in the Selected Tertiary Hospital at Bhubaneswar
}

\author{
Mousumi Paul', Niyati Das' ${ }^{2}$, Purnima Sahoo ${ }^{3}$
}

${ }^{1}$ M.Sc. Nursing, Child Health Nursing, (Kalinga Institute of Nursing Sciences, KIIT Deemed to be university, Bhubaneswar, Odisha) and Assistant Professor, International Institute of Nursing \& Research, Kalyani, Nadia, West Bengal, India.

${ }^{2}$ Professor Cum Vice Principal, RNRM, M.SC (N). in Child Health Nursing, H.O.D, Dept. of Pediatric Nursing- Kalinga Institute of Nursing Sciences, KIIT Deemed to be University, Bhubaneswar, Odisha, India.

${ }^{3}$ Asst. Professor, RNRM, M.Sc. (N) in Child Health Nursing- Kalinga Institute of Nursing Sciences, KIIT Deemed to be University, Bhubaneswar, Odisha, India.

DOI: https://doi.org/10.24321/2581.5822.202008

I $\quad \begin{array}{llll}\mathbf{N} & \mathbf{F} & \mathbf{O}\end{array}$

\section{Corresponding Author:}

Mousumi Paul, (Kalinga Institute of Nursing Sciences, KIIT Deemed to be university, Bhubaneswar, Odisha) and Assistant Professor, International Institute of Nursing \& Research, Kalyani, Nadia, West Bengal, India.

E-mail Id:

paulmousumi2341992@gmail.com

Orcid Id:

https://orcid.org/0000-0003-1383-789X

How to cite this article:

Paul M, Das N, Sahoo P. Effectiveness of Play Therapy during Hospitalization in reducing Anxiety among 6-12 Years Children in the Selected Tertiary Hospital at Bhubaneswar. J Adv Res Psychol Psychother 2020; 3(3\&4): 8-14.

Date of Submission: 2020-11-15

Date of Acceptance: 2020-12-29
$\begin{array}{llllllll}\mathbf{A} & \mathbf{B} & \mathbf{S} & \mathbf{T} & \mathbf{R} & \mathbf{A} & \mathbf{C} & \mathbf{T}\end{array}$

Background: Hospitalization can be a threatening and stressful experience for children. Because of unfamiliar with the environment and medical procedures and unaware of the reasons for hospitalization, it can result in children's anger, anxiety.

Objectives: The objectives of the study are to do the baseline assessment of anxiety score of hospitalized children of experimental and control group, to assess the effectiveness of play therapy and to assess the pre and post intervention score of anxiety across different sub group of anxiety disorder like Separation anxiety, Social phobia, OCD, Panic/ agoraphobia, Physical injury fears, Generalized anxiety.

Methods: Randomized clinical control trial design with control group was used and the formal consent was obtained from Pradyumna Bal Memorial Hospital and the investigator selected 60 samples using consecutive sampling technique (taking every patient who met the selection criteria over the specified time period) and then randomized into experimental and control groups. Measurement of anxiety experienced by the school going children was assessed with the help of Spence Children Anxiety Scale. Descriptive and inferential statistics were used to analyze the data.

Result: The mean anxiety score of children in control group was 39.4 and the experimental group was 34.433 . The $p$ value in comparing the anxiety score of children in control and experimental group was 0.004 , which was statistically significant at $p<0.01$ level indicating that there was significant difference in the post test level of anxiety between the control and experimental group.

Conclusions: The study was concluded that play therapy was effective in reducing the anxiety among school going children.

Keywords: Play Therapy, Anxiety, Hospitalized Children 


\section{Introduction}

Play is a universal medium for all children. It is pleasurable and enjoyable aspect of child's life and essential to promote growth and development. Play is a transaction between the child and the environment which is intrinsically motivated, internally controlled and not bound by objective reality. Various forms of play at different ages provide opportunities for children to learn themselves, about the world and about interacting with others. Above all play serves as a mechanism for maintaining the children sense of equilibrium. ${ }^{1}$

Play is the main business of children's lives. It is not a peripheral fun activity, but the key to development in many areas. Deprived of play the child is a prisoner, shut off from all that makes life real and meaningful. Play is one of the ways in which a child develops capacities to deal with the stresses and strains of life as they press upon them. It acts as a safety valve, allowing them to relieve, and often come to terms with fears and anxieties which have become overwhelming. ${ }^{2}$

\section{Need of the Study}

Children in the hospital need play provision not only because they have natural needs for play but also for other reasons such as to prevent developmental regression, to reduce parental and child stress and anxiety, to facilitate communication between staff and children and to encourage the child cooperation in hospital procedures. ${ }^{3}$

Admission to a hospital is threatening for a child and they often report about anxiety, discomfort during hospital stay. When the child is admitted to a hospital his/her daily routine and normal life get hampered. ${ }^{4}$

Schoolers may experience severe hospital related fears and ongoing traumatic stress responses during hospitalization and post discharge. Hospitalization and other frightening traumatic experiences in childhood may also increase the risk of health problems later in life and delay the child's cognitive, physical, emotional and social development. ${ }^{4}$

\section{Statement of the Problem}

Effectiveness of play therapy on anxiety reduction among hospitalized children in a selected tertiary hospital, Bhubaneswar, Odisha.

\section{Hypothesis}

There is a significant reduction on anxiety score among hospitalized children after play therapy in experimental group.

\section{Objectives}

- To do the baseline assessment of anxiety of hospitalized child of experimental and control group

- To assess the effectiveness of play therapy
- To assess the pre and post intervention score of anxiety across different sub group of anxiety disorder like Separation anxiety, Social phobia, OCD, Panic/ agoraphobia, Physical injury fears, Generalized anxiety

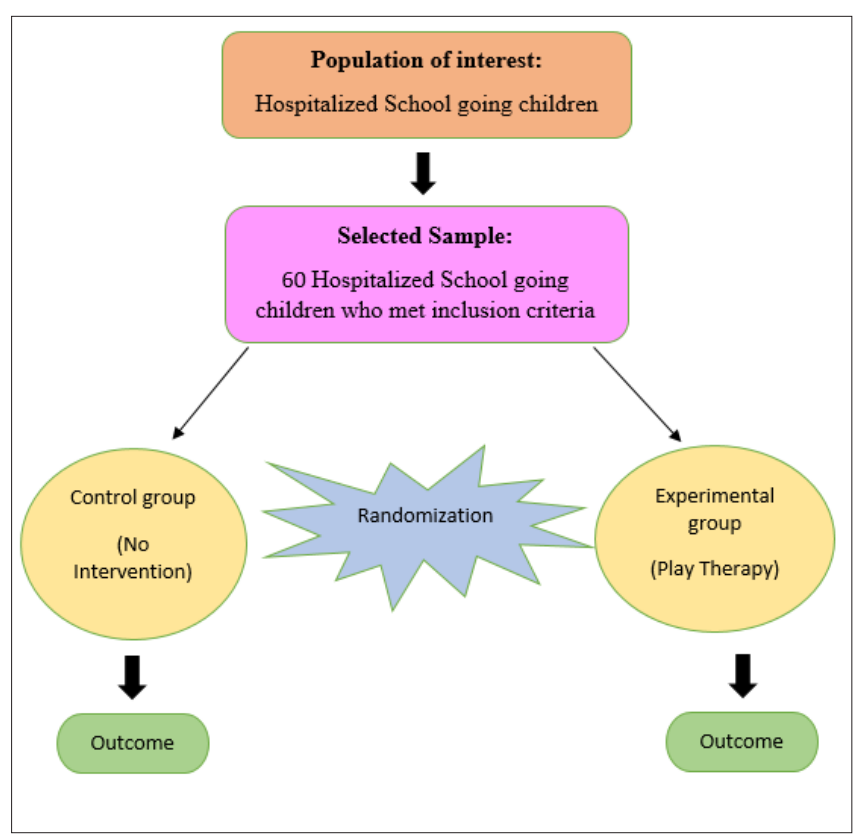

Figure 2.Schematic diagram of the research design Methodology

Research Approach: Quantitative research approach is used for this study.

Research Design: Randomized controlled clinical trial.

Independent Variables: In this study independent variable was the play therapy among hospitalized child.

Dependent Variables: In this study dependent variable was anxiety of hospitalized child.

Research Setting: the study was conducted pediatric ward of Pradyumna Bal Memorial Hospital, KIMS.

Target Population: Children of pediatric ward.

Sample: The samples selected for the present study were schooler children of Pradyumna Bal Memorial Hospital, KIMS.

Sample Size: In this study sample consists of 60 school going children who met the inclusion criteria.

Sampling Technique: The sample was selected for this study by adopting Consecutive Sampling (taking every patient who meets the selection criteria over the specified time period) and then randomized into experimental and control groups.

By considering the reduction of anxiety score of 35 unit in the experimental group as compared to control group and reported SDs of 24 units and 15 units respectively for 
control and experimental group at $1 \%$ level of significance and $90 \%$ of study power, the required sample size is 23 in each group. By presuming a lost to follow up of $25 \%$, an addition of 7 child will be added in each group. Accordingly, a total of 60 subjects are required for the current study (30 subject for each group).

\section{Inclusion Criteria}

- School going Children (6 years to 12 years)

- Child admitted in general ward

- Both Male \& female child

- Parents who are giving consent to allow their children to participate

\section{Exclusion Criteria}

- Children's who are admitted in pediatric Intensive care unit

- Whose parents do not give consent

- Syndromic child, neurodevelopmental disorder

Duration of Study: The sudy was conducted from July 2017 to May 2018.

\section{Ethical Consideration}

For this study, the investigator took into consideration the ethical issues.

- The study was accepted by the research committee of KIMS and prior to permission was obtained from the KIMS authority, Bhubaneswar to conduct a final study

- The study was accepted by the ethics committee of KIMS and prior to permission was obtained from the KIMS authority, Bhubaneswar to conduct of final study

- Written consent of the subject was obtained

- The purpose of the study was explained to the parent and also children

- Anonymity of the objects was maintained by assigning code numbers to all subjects under the study

- The subjects were assured that confidentiality of the information will be maintained and information will be used only for the purpose of the study. They had freedom to withdraw from the study at any time without giving any reason

- No ethical issues confronted while conducting the study

\section{Schematic Diagram of Research Methodology}

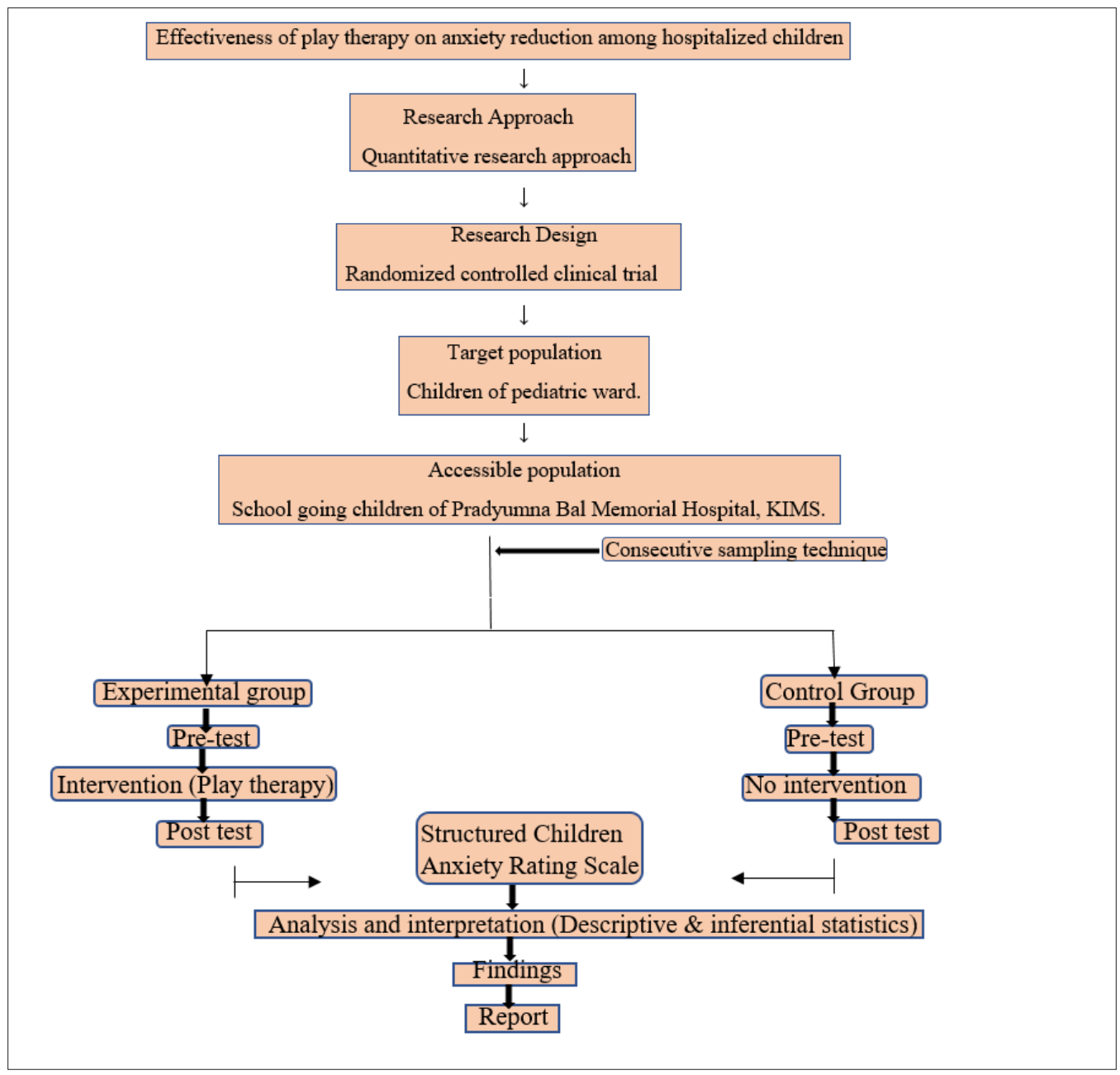




\section{Description of Tool}

\section{Section I: Socio-Demographic Data}

Socio-Demographic data of the subjects consists of the following items: Age, Gender, Birth order of the child, Residence, Type of family, Religion, Occupation of the father, Educational qualification of the father, Occupation of the mother, Educational qualification of the mother, Family income, Sibling rivalry, Father's addiction, previous hospitalization within one year.

\section{Section II: Spence Children's Anxiety Scale}

The Spence Children's Anxiety Scale (SCAS) is a psychological questionnaire. It can identify social phobia, anxiety disorder, obsessive-compulsive disorder, panic disorder/agoraphobia in children aged between 8 and 15. SCAS developed by Susan $\mathrm{H}$. Spence. It is available in various languages. It consists of 45-question which can be filled by the child or parent. The test takes approximately 5 to 10 minutes to complete. The questionnaire has shown good reliability and validity in recent studies.

Each question on the test addresses the frequency of certain anxiety symptoms, measured on a 0-3 scale from "never," "sometimes," often," to "always."

\section{Data Collection Procedure}

This is a study that will be conducted in the play room of PBMH hospital, in which the effect of play therapy will be seen on anxiety reduction among hospitalized children. The children will be randomized into two groups: experimental group (30 samples) and control group (30 samples). First the study will be explained to the mothers and an informed consent will be taken before starting the study.

Then sociodemographic data of the child will be collected and then pre-test will be conducted on the basis of structured anxiety rating scale (both experimental and control group). On the next day the play activities will be administered to the sample. The play activities will be continued period of 4 days and a conducted post-test by using the same structured anxiety rating scale on the $6^{\text {th }}$ day.

\section{Data Analysis}

Section 1: Pattern of Socio-Demographic Characteristics Between Experimental and Control Group

This section deals with the demographic characteristics of the respondents. The data pertaining to the demographic variables of respondents inside age, gender, birth order, residence, family, religion, father's education, father's occupation, mother's education, mother's occupation, family income, sibling rivalry, father's addiction and previous hospitalization.

Table I(I). Mean score of age in control \& experimental group

\begin{tabular}{|c|c|c|}
\multicolumn{2}{c}{$\mathrm{N}=60(\mathrm{n} 1=30, \mathrm{n} 2=30)$} \\
\hline Group & $\begin{array}{c}\text { Mean } \pm \text { Standard } \\
\text { deviation }\end{array}$ & p- value \\
\hline Age in Control group & $8.867 \pm 2.096$ & 0.359 \\
\hline $\begin{array}{c}\text { Age in Experimental } \\
\text { group }\end{array}$ & $9.367 \pm 2.092$ & \\
\hline
\end{tabular}

Table 1(1), shows that mean score of age in control group was 9.367 \& in experimental group was 8.867 which was not statistically significant.

Table 1(2), shows that demographical factors were not statistically significant.

Table I(2).Frequency and percentage distribution of gender in control \& experimental group

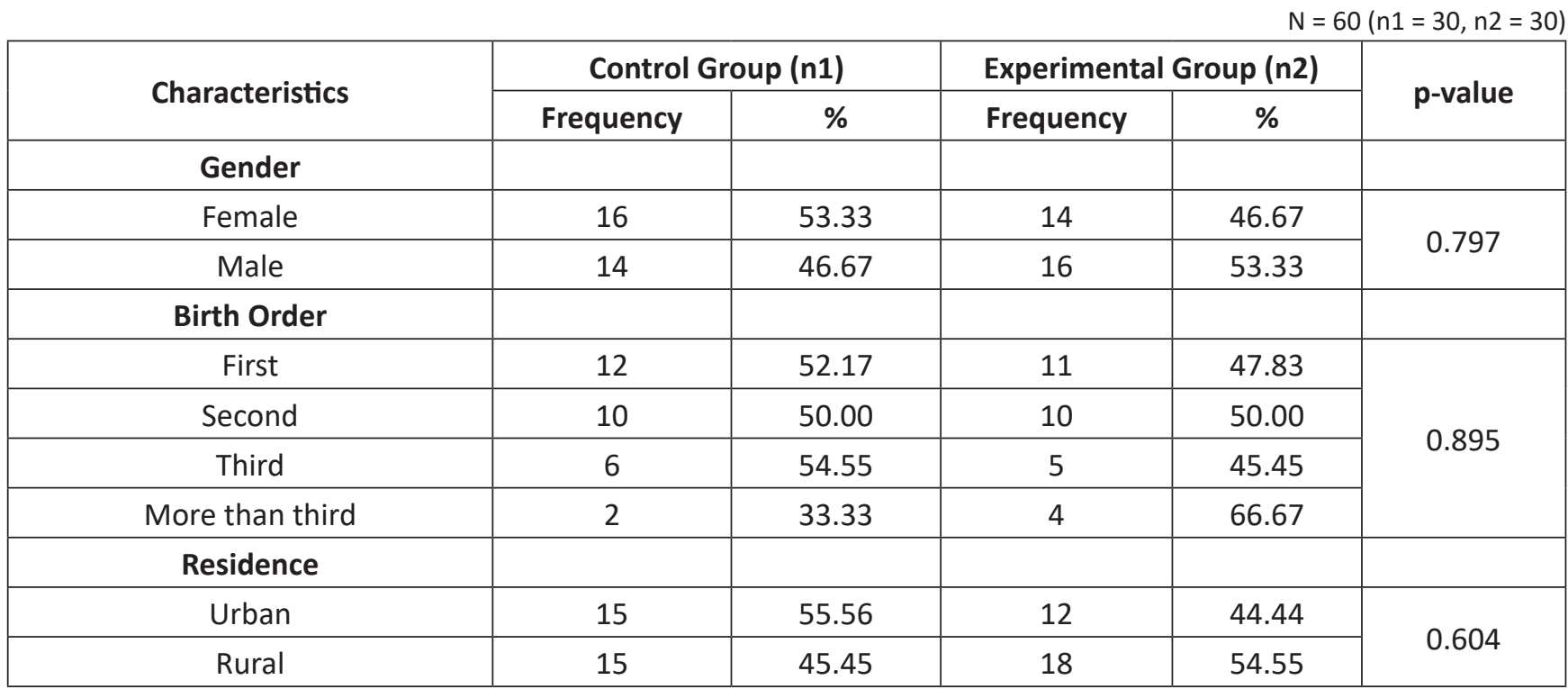




\begin{tabular}{|c|c|c|c|c|c|}
\hline Type of family & & & & & \\
\hline Nuclear & 16 & 48.48 & 17 & 51.52 & 1.000 \\
\hline Joint & 14 & 51.85 & 13 & 48.15 & \\
\hline \multicolumn{6}{|l|}{ Mother's Education } \\
\hline Illiterate & 5 & 41.67 & 7 & 58.33 & \multirow{5}{*}{0.765} \\
\hline Primary & 9 & 45.00 & 11 & 55.00 & \\
\hline Secondary & 8 & 57.14 & 6 & 42.86 & \\
\hline Higher secondary & 7 & 63.64 & 4 & 36.36 & \\
\hline Graduate \& above & 1 & 33.33 & 2 & 66.67 & \\
\hline \multicolumn{6}{|l|}{ Mother's Occupation } \\
\hline Housewife & 21 & 45.65 & 25 & 54.35 & \multirow{3}{*}{0.496} \\
\hline Service & 5 & 62.50 & 3 & 37.50 & \\
\hline Laborer & 4 & 66.67 & 2 & 33.33 & \\
\hline \multicolumn{6}{|l|}{ Family Income } \\
\hline < Rs. 10,000 & 11 & 61.11 & 7 & 38.89 & \multirow{4}{*}{0.645} \\
\hline Rs. $10,000-20,000$ & 9 & 42.86 & 12 & 57.14 & \\
\hline Rs. $20,000-30,000$ & 6 & 42.86 & 8 & 57.14 & \\
\hline > Rs. 30,000 & 4 & 57.14 & 3 & 42.86 & \\
\hline \multicolumn{6}{|l|}{ Sibling Rivalry } \\
\hline Regular & 2 & 50.00 & 2 & 50.00 & \multirow{3}{*}{0.830} \\
\hline Intermittent & 21 & 53.85 & 18 & 46.15 & \\
\hline Absent & 7 & 41.18 & 10 & 58.82 & \\
\hline \multicolumn{6}{|l|}{ Previous hospitalization } \\
\hline None & 1 & 11.11 & 8 & 88.89 & \multirow{3}{*}{0.028} \\
\hline One time & 16 & 51.61 & 15 & 48.39 & \\
\hline More than one time & 13 & 65.00 & 7 & 35.00 & \\
\hline
\end{tabular}

Section 2: Findings related to Difference of Anxiety Score between Control and Experimental Group in Pretest

Table 2.Difference of anxiety score between control and experimental group in pretest (Independent t-test)

\begin{tabular}{|c|c|c|c|}
\hline \multicolumn{4}{|c|}{$N=60(\mathrm{n} 1=30, \mathrm{n} 2=30)$} \\
\hline Scoring system & Control $(\mathbf{n} 1)$ mean \pm SD & Experimental $(\mathbf{n} 2)$ mean $\pm S D$ & p-value \\
\hline Total pretest & $41.2 \pm 6.979$ & $43.567 \pm 5.793$ & 0.158 \\
\hline Separation anxiety pretest & $10.367 \pm 2.498$ & $10.067 \pm 1.721$ & 0.590 \\
\hline Social phobia pretest & $4.9 \pm 1.729$ & $6.333 \pm 1.899$ & 0.003 \\
\hline Obsessive compulsive pretest & $2.2 \pm 2.024$ & $1.5 \pm 1.526$ & 0.136 \\
\hline Panic pretest & $5.3 \pm 1.914$ & $5.767 \pm 1.675$ & 0.319 \\
\hline Physical injury fear pretest & $10.767 \pm 3.159$ & $11.667 \pm 2.440$ & 0.222 \\
\hline Generalized anxiety pretest & $7.667 \pm 2.975$ & $8.233 \pm 2.402$ & 0.420 \\
\hline
\end{tabular}
$p=0.01$

Table 2, Shows the total pretest score in control and experimental group were 41.2 and 43.567 respectively.
Here calculated $p$-value 0.158 and tabulated $p$-value 0.01 , as calculated $p$-value was more than tabulated $p$-value. 
So, there was no significant difference between control and experimental group in pretest and it was statistically not significant.

Social phobia Pretest score in control and experimental group was statistically significant but other subscales were not statistically significant.

Section 3: Findings related to Difference of Anxiety Score between Control and Experimental Group in Post-test
Separation anxiety, Social phobia, Obsessive compulsive, Panic, Physical injury fear and Generalized anxiety posttest score in control and experimental group were not statistically significant.

Section 4: Findings related to Difference of Anxiety Score between pre and post-test in Control and Experimental Group

Table 4, shows total score during pre-test and post-test

Table 3.Difference of anxiety score between control and experimental group in posttest (Independent t-test)

\begin{tabular}{|c|c|c|c|}
\hline \multicolumn{3}{|c|}{$\mathrm{N}=60(\mathrm{n} 1=30, \mathrm{n} 2=30)$} \\
\hline Scoring system & Control $(\mathbf{n} 2)$ mean \pm SD & Experimental $(\mathbf{n} 1)$ mean $\pm S D$ & p-value \\
\hline Total post-test & $39.4 \pm 7.514$ & $34.433 \pm 5.063$ & 0.004 \\
\hline Separation anxiety post-test & $8.867 \pm 2.687$ & $7.7 \pm 1.822$ & 0.054 \\
\hline Social phobia & $4.7 \pm 1.725$ & $5 \pm 1.819$ & 0.515 \\
\hline Obsessive compulsive post-test & $2.2 \pm 2.024$ & $1.633 \pm 1.847$ & 0.262 \\
\hline Panic post-test & $5.3 \pm 2.231$ & $4.333 \pm 1.348$ & 0.047 \\
\hline Physical injury fear post-test & $10.7 \pm 3.334$ & $9.567 \pm 2.029$ & 0.117 \\
\hline Generalized anxiety post-test & $7.633 \pm 2.882$ & $6.4 \pm 2.143$ & 0.065 \\
\hline
\end{tabular}
$p=0.01$

Table 3, shows the total Posttest score in control and experimental group were 39.4 and 34.433 respectively. Here calculated $p$-value 0.004 and tabulated $p$ value 0.01 , as calculated $p$-value was less than tabulated $p$-value. So, there was significant difference between control and experimental group in posttest and it was statistically significant. were compared separately in control and experimental group. Mean total score during pre-test and post-test were 41.2 and 39.4 respectively observed in control group which was found to statistically significant. Similarly, the total score during pretest and post-test were 43.567 and 34.433 respectively observed in experimental group and also found statistically significant with a substantial difference.

Table 4.Difference of anxiety score between pre and post-test in control and experimental group (Paired t-test)

\begin{tabular}{|c|c|c|c|c|}
\hline \multicolumn{5}{|c|}{$\mathrm{N}=60(\mathrm{n} 1=30, \mathrm{n} 2=3$} \\
\hline Scoring system & Group & Pre-test Mean \pm SD & Post-test Mean $\pm S D$ & $p$-value \\
\hline \multirow{2}{*}{ Total score } & Control (n1) & $41.2 \pm 6.979$ & $39.4 \pm 7.514$ & $<0.01$ \\
\hline & Experimental (n2) & $43.567 \pm 5.793$ & $34.433 \pm 5.063$ & $<0.01$ \\
\hline \multirow{2}{*}{ Separation Anxiety score } & Control (n1) & $10.367 \pm 2.498$ & $8.867 \pm 2.687$ & $<0.01$ \\
\hline & Experimental (n2) & $10.067 \pm 1.721$ & $7.7 \pm 1.822$ & $<0.01$ \\
\hline \multirow{2}{*}{ Social phobia score } & Control (n1) & $4.9 \pm 1.729$ & $4.7 \pm 1.725$ & 0.083 \\
\hline & Experimental (n2) & $6.333 \pm 1.899$ & $5 \pm 1.819$ & $<0.01$ \\
\hline \multirow{2}{*}{$\begin{array}{l}\text { Obsessive compulsive } \\
\text { score }\end{array}$} & Control (n1) & $2.2 \pm 2.024$ & $2.2 \pm 2.024$ & -- \\
\hline & Experimental (n2) & $1.5 \pm 1.526$ & $1.633 \pm 1.847$ & 0.636 \\
\hline \multirow{2}{*}{ Panic } & Control (n1) & $5.3 \pm 1.914$ & $5.3 \pm 2.231$ & 1.000 \\
\hline & Experimental (n2) & $5.767 \pm 1.675$ & $4.333 \pm 1.348$ & $<0.01$ \\
\hline \multirow[t]{2}{*}{ Physical injury fear score } & Control (n1) & $10.767 \pm 3.159$ & $10.7 \pm 3.333$ & 0.752 \\
\hline & Experimental (n2) & $11.667 \pm 2.440$ & $9.567 \pm 2.029$ & $<0.01$ \\
\hline \multirow{2}{*}{ Generalized anxiety score } & Control (n1) & $7.667 \pm 2.975$ & $7.633 \pm 2.882$ & 0.861 \\
\hline & Experimental (n2) & $8.233 \pm 2.402$ & $6.4 \pm 2.143$ & $<0.01$ \\
\hline
\end{tabular}




\section{Discussion \\ Objective I}

The findings of this study revealed that during pretest mean anxiety score 41.2 in control group, whereas in the experimental group, pretest mean anxiety score 43.567.

Here calculated $p$-value 0.158 and tabulated $p$-value 0.01 , as calculated $p$ value was more than tabulated $p$ value. So, there was no significant difference between control and experimental group in pretest and it was statistically not significant.

\section{Objective 2}

The findings of this study reveal that (independent t-test) mean post-test anxiety score in control group and experimental group were 39.4 and 34.433 respectively. Here calculated $p$-value was 0.004 and tabulated $p$ value was 0.01 , as calculated $p$-value was less than tabulated $\mathrm{p}$-value. So, there was significant difference between control and experimental group in post-test and it was statistically significant. So, play therapy was effective in reduction of anxiety score of hospitalized children.

In a similar study, in experimental posttest mean score, 37.87 and SD was 14.708 respectively. The obtained $\mathrm{t}$-value 14.015 statistically was significant at 0.000 level. So, research hypothesis was accepted, in comparison of mean score of experimental post - test and control post test that the obtained $\mathrm{t}$-value is 8.165 statistically valued was .000 so it is significant $(<0.05)$ therefore research hypothesis was accepted so it clearly shows that the level of anxiety was reduce in experimental group in posttest. ${ }^{5}$

Another similar study where samples for the study were chosen by purposive sampling and the sample size was 30 in experimental group and 30 in control group. The findings of the study revealed that in control group there was no significant difference in the mean and standard deviation of the anxiety scores $(M=49.5,48.4 \& S D=8.30,8.36)$ before and after play therapy. Whereas in experimental group significant difference in the mean and standard deviation of anxiety score $(M=49,42.76 \& S D=8.40,8.29)$ was noted before and after play therapy at $p<0.01$. Overall study findings have identified the play therapy is effective in reducing the anxiety among hospitalized children. ${ }^{6}$

\section{Objective 3}

Mean anxiety total score during pre-test and post-test were 41.2 \& 39.4 respectively observed in control group which was found statistically significant. Similarly, the anxiety total score during pre-test and post-test were 43.567 \& 34.433 respectively observed in experimental group and also found statistically significant.

In control group the difference between pre-test and post- test of anxiety score was less as compared to experimental group may be due the adaptation to hospital environment but as there was more difference of pretest and post-test anxiety score in experimental group so it can be concluded that the play therapy as a measure of anxiety reduction among hospitalized children was very effective.

Mean score of anxiety were substantially different between pre-test and post-test in experimental group than the control group. Hence, it can be inferred that there was no much anxiety reduction in the control group as in interventional group. So, play therapy is effective for reduction of anxiety of hospitalized school going children.

\section{Conclusion}

After play therapy session, it was found that there had been a significant level of reduction in level of anxiety of hospitalized children. It is thus concluded that, play therapy is an effective and simple strategy to reduce anxiety among hospitalized children.

\section{Conflict of Interest: None \\ References}

1. Dutta P. Pediatric Nursing. New Delhi: Jaypee Brothers Medical Publishers (P) Ltd; 2009.

2. Nisha K, Umarani J. Effect of play intervention in the reduction of anxiety among preoperative children. IJCRR 2013; 5(11):104 - 110. https://pdfs.semanticscholar. org/9a5a/2208b9de726e404bd9a2fb071d19e048e656. pdf (accessed 4 April 2018).

3. Catharine. What is it findings on preschooler's response to play with medical equipment. Child care health development 2001; 27(5): 451-462.

4. William B C. editor. Developmental Behavioral Pediatrics 4th ed. [eBook]. Elsevier Health Sciences; 2008 [cited 2009 Apr 30]. Available from: Ebrary.

5. Sen S. A study to assess the effectiveness of play therapy on anxiety among hospitalized children. International Journal of Advanced Research 2017; 5(8): 1540-1546. http://www.journalijar.com/article/19530 (accessed 10 April 2018).

6. Davidson B, Satchi NS, Venkatesan L. Effectiveness of play therapy upon anxiety among hospitalised children. IJARIIT 2017; 3(5): 441. https://www.ijariit. com/manuscripts/v3i5/V3I5-1295.pdf (accessed 10 April 2018). 